\title{
INNOVATIVE STRATEGIES FOR ENERGY OPTIMIZATION
}

\author{
S. Bottillo ${ }^{1}$, L. Cedola ${ }^{2}$, R. de Lieto Vollaro ${ }^{3}$, A. Vallati $^{4}$ \\ ${ }^{1}$ Ph.D. Student, ${ }^{4}$ Assistant Professor, DIAEE, Sapienza University of Rome, Rome, Italy \\ ${ }^{2}$ Assistant Professor, DIMA, Sapienza University of Rome, Italy \\ ${ }^{3}$ Assistant Professor, Department of Engineering, University of Roma Tre, Rome, Italy, \\ simone.bottillo@uniroma1.it,luca.cedola@uniroma1.it,roberto.delietovollaro@uniroma3.it, \\ andrea.vallati@uniroma1.it
}

\begin{abstract}
Optimization of energy production systems is a relevant issue that must be considered in order to follow the fossil fuels consumption reduction policies and the CO2 emission regulation. Increasing electricity production from renewable resources (e.g. photovoltaic systems and wind farms) is desirable but its unpredictability is a cause of problems for the main grid stability. The multi-energy system represents an efficient solution, by realizing an interface among renewable energy sources, energy storage systems and conventional power generators. Direct consequences of multi-energy systems are wider energy flexibility and benefits for the electric grid. In this study the performances of a multi-energy system in dynamic regime have been evaluated and a comparison with a conventional system has been performed. The results show how this innovative energetic approach can provide a cost reduction in power supply and energy fees of $40 \%$ and $25 \%$ respectively and CO2 emission decrease attained around 18\%. Furthermore, the multi-energy system taken as case of study has been optimized through the utilization of three different type of energy storage (Pb-Ac batteries, Flywheels and Micro-Caes).
\end{abstract}

\section{Keywords: Multi-Energy System, Cost of Energy, Energy Storage}

\section{INTRODUCTION}

The rise of $\mathrm{CO} 2$ level in the atmosphere is the main responsible for global warming and the international community set a deadline to achieve some targets in the Kyoto Protocol. The European Union accepted the recommendations established in the agreement and it has outlined a strategy in order to achieve three different targets (called 20-20-20) within 2020: the $20 \%$ reduction of greenhouse gases emissions, the $20 \%$ increase of energy production from renewable sources and the $20 \%$ increase of energy efficiency [1-2]. The following guidelines have been outlined: promoting the electricity distribution grid with generators connected, incentivizing the energy production from renewable sources and from CHP systems (combined heat and power) applied in residential, service and commercial sectors, developing the sustainable mobility through the utilization of electric vehicles, promoting a rational use of electricity in order to decrease the energy consumption. For this reason, it is necessary to study multi-energy or hybrid systems: systems which use two or more energy sources, energy converters, fuels [3] in order to meet the energy demand of a user which can be a single building, a group of buildings or a factory. These systems are inherently flexible and allow to exploit the renewable sources in the best way, following thermal and electric demands, increasing the reliability of service continuity through the utilization of CHP generators and reducing operation costs. Multi-energy systems play a crucial role in a political context inclined to the distributed generation. It is possible to control the power production and energy demand providing a valuable contribution to the stabilization of the electric main grid, by including energy storage systems and endothermic generators. It is necessary to communicate with a "smart grid" by exchanging information and by controlling the energy flows, in order to produce: an increase of energy saving, a reduction of pollutant emissions, the possibility of realizes stand-alone systems, relieving congestion in the electric grid during the peak hours of the day [4]. As the technology of electronic devices continue to improve, a perfect management of systems connected to different kind of energy storage (electric and thermal) can be realized. The optimal management of energetic flows in complex systems must be managed by an important device: the energy hub (a smart system used to analyze the situation and manage the components of the plant efficiently). It has been demonstrated that an efficient energy-hub produces a remarkable reduction of costs, greenhouse gases emissions and energy saving [5]. The energy-hub is considered as unit where the energetic flows are converted, conditioned and eventually stored [6]; as input it requires an amount of energy (electric energy from the grid, natural gas, energy from renewable sources) and it ensures the supply for several services, such as: electric and thermal energy, cooling, compressed air, etc. The redundant connections that could be established between input and output inside the energy-hub have two significant consequences: an increase of reliability of 
resources supply and the most advantageous choice among the various options. Brenna et al. [7] proposed a model that allows integration between different independent subsystems, such as final users and high efficiency buildings, with CHP in a Sustainable Energy Microsystem (SEM), aimed at the management of the city of the future, the smart-city. The aim of this study is to evaluate a multi-energy system through a dynamic analysis of performance, in order to obtain a primary energy saving, a reduction of operating costs and $\mathrm{CO} 2$ emissions, compared to a conventional plant. It will be also shown how the various plant components must operate in order to obtain the desired savings. Moreover, three different kind of electric storage will be considered, in order to evaluate their impact by changing key parameters. An economic and financial assessment will be carried out in order to verify the investment feasibility, which is the necessary condition for the plant realization.

\section{NUMERICAL MODELS}

In this study a system of analysis and optimization through the utilization of two mathematical models in cascade, is proposed. The study of heat exchanges and electricity is performed through a dynamic system, using the software TRNSYS [8]; the obtained results are used as inputs for Homer Energy [9] that is used to perform the energetic optimization process and to evaluate the economic benefit of the investment. The implemented model is based on the time series: for every time step the model solves the energy balance for each component and correlates it with the other components of the same system. For each component, the model evaluates the costs of energy production, giving priority to the lower ones. The evaluation of the costs is carried out considering the cost of investment, maintenance and fuel purchase.

\section{CASE OF STUDY}

In this study, it has been chosen to perform an upgrade of energy efficiency of an area characterized by continuous operations during the day and high power consumption; furthermore the presence of large spaces solves the problems of plant installation.
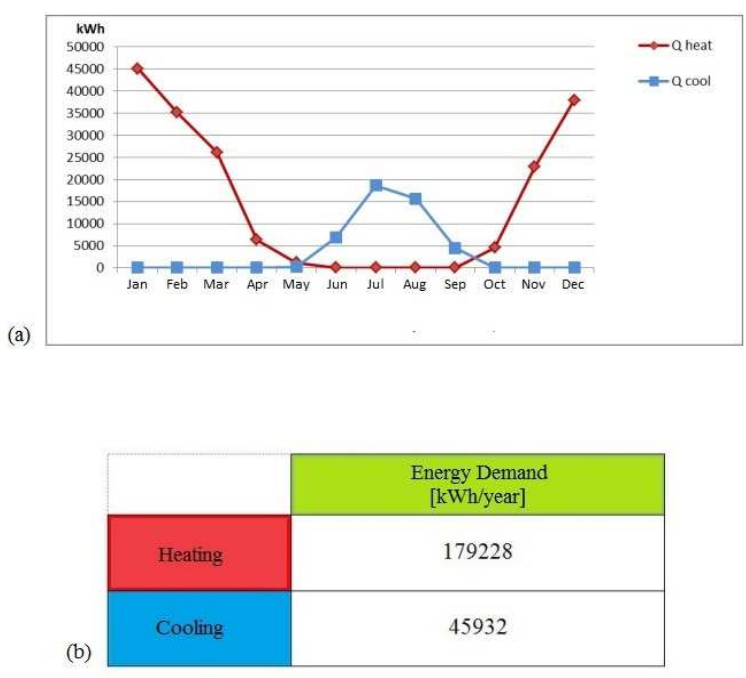

Fig -1: (a) Yearly trend of energy demand for heating (Q heat) and cooling (Q cool), obtained with TRNSYS; (b) Yearly total energy demand $[\mathrm{kWh} /$ year] for heating and cooling.

The structure is characterized by a surface area of $1600 \mathrm{~m}^{2}$ and a volume of $8000 \mathrm{~m}^{3}$. Currently the plant is constituted by a diesel fired boiler $(400 \mathrm{~kW})$ for the heating and the hot water production, and two refrigeration units (each one $140 \mathrm{~kW}$ ). The energy demand of the structure during the year has been studied, through a dynamic analysis; in Fig.1 (a)(b) are shown the results. In Fig. 2 is shown the trend of electric power absorbed from the grid during the year; it can be observed that the electricity demand is continuous; the average value is 150 $\mathrm{kW}$ and total electricity demand during the year is 1315624 $\mathrm{kWh}$. The cost of energy consumption and diesel oil purchase, in 2012, has been $268942 €$; the Net Present Cost for 20 years of operation is $3573.822 €$ and the yearly $\mathrm{CO}_{2}$ emission is 765.7 t/year.

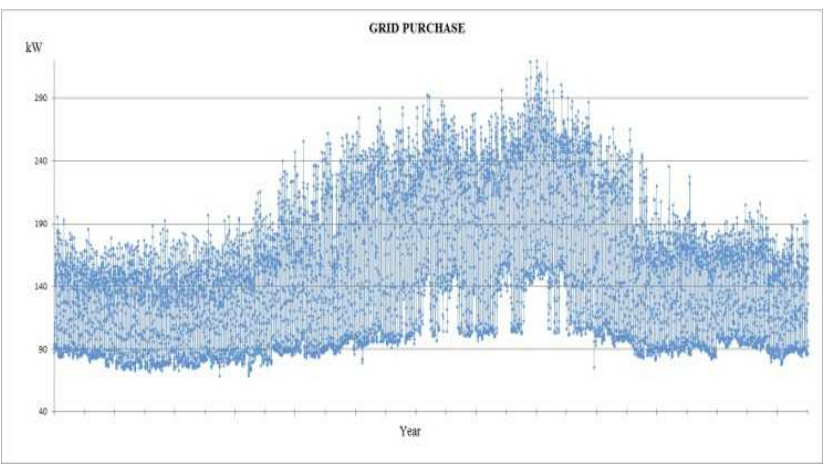

Fig -2: Yearly trend of electricity purchased from the grid 


\section{ALTERNATIVE SOLUTION: MULTI-ENERGY SYSTEM}

In order to obtain a reduction of fuel consumption, cost of energy and $\mathrm{CO}_{2}$ emissions, the implementation of a multienergy system has been proposed (Fig.3). It consists of a CHP reciprocating internal combustion engine and photovoltaic panels $(100 \mathrm{kWp})$; the engine is supplied by natural gas that has a lower carbon content compared to diesel fuel. The thermal load is satisfied by CHP engine and by an integrated boiler fueled by natural gas. The price of natural gas, considering the tax relief, is $0.469 € / \mathrm{nm}^{3}$; the price of electricity depends by the time slot $(0.18 € / \mathrm{kWh}, 0.15 € / \mathrm{kWh}$ and $0.10 € / \mathrm{kWh}$ ). For generators characterized by an electric capacity lower than $200 \mathrm{~kW}$, it is possible to carry out the onsite exchange, by inserting into the grid the excess of electric production; the sale price has been set at $0.09 € / \mathrm{kWh}$. The unit costs of the components are: for photovoltaic panels, $2500 € / \mathrm{kW}$, for the inverter, $300 € / \mathrm{kW}$, for the CHP engine, $1500 € / \mathrm{kW}$. For the optimization process, several simulations have been considered in order to compare three different sizes of CHP engine (100 kW, $150 \mathrm{~kW}$ and $200 \mathrm{~kW})$. Regarding the electric power absorbed from the grid, two constrains have been imposed: $100 \mathrm{~kW}$ and $150 \mathrm{~kW}$, which obviously have an influence on operating hours of the generator. Therefore, six simulations have been performed. Fig. 4 shown the Net Present Cost for each configuration considered and for the current plant. It can be observed that there aren't remarkable differences among the six configurations; even though the configurations 4 and 6 are characterized by the highest cost of investment, they have also the highest profits due to the increase of self-generated energy and to the relative increase of sale of White Certificates.

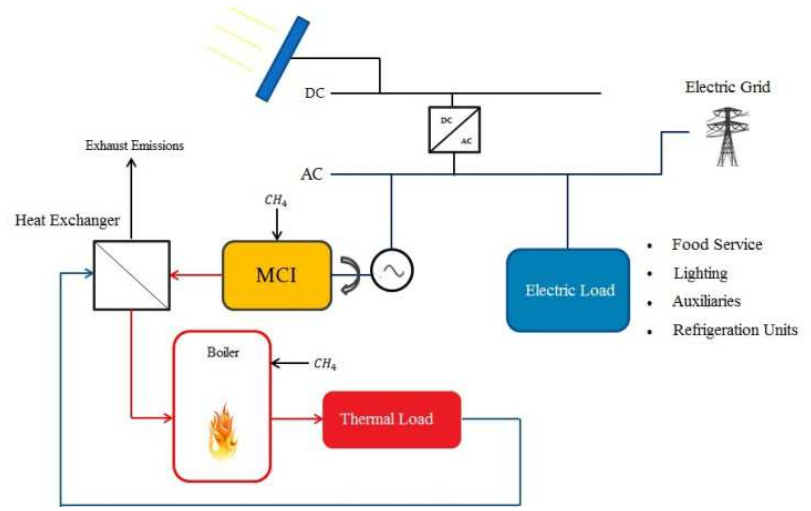

Fig -3: Multi-energy system implemented in Homer Energy

From the economic point of view the configuration 1 is the best, followed by the configuration 4 which is a compromise between all the configurations. In Fig. 5 the distribution of electricity production for the six configurations considered, is shown; as it can be seen, for configuration 1,2 and 3, the amount of energy purchased from the grid is approximately $50 \%$, while for configurations 4,5 and 6 it tends to decrease up to $11 \%$.

\begin{tabular}{|c|c|c|}
\hline Configuration & $\begin{array}{l}\text { CHP } \\
{[\mathrm{kW}]}\end{array}$ & $\begin{array}{l}\text { Grid } \\
{[\mathrm{kW}]}\end{array}$ \\
\hline 1 & 100 & 150 \\
\hline 2 & 150 & 150 \\
\hline 3 & 100 & 100 \\
\hline 4 & 200 & 150 \\
\hline 5 & 150 & 100 \\
\hline 6 & 200 & 100 \\
\hline
\end{tabular}

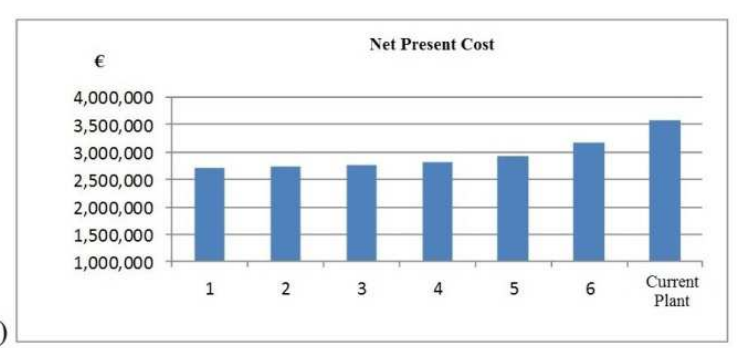

Fig -4: (a) Configurations considered; (b) Net Present Cost of the configurations considered and the current plant.

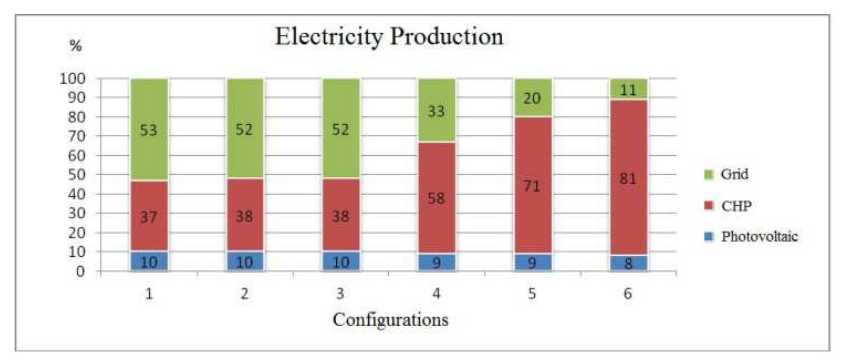

Fig -5: Distribution of electricity production for the six configurations.

Once again two different scenarios are proposed: for the first three configurations, there is a strong dependence on the price of electricity, on the other hand, configuration 5 and 6 are characterized by a strong dependence of natural gas price; configuration 4 represents a good compromise among the others. From thermal point of view, it can be observed how the CHP supplies the thermal load (Fig. 6); in all configurations there is a sufficient production of heat and the use of boiler is mainly concentrated in the hours when the CHP is off. Even in configuration 1, where CHP size is $100 \mathrm{~kW}$, the heat produced by the boiler is less than $20 \%$. Fig. 7 shows the value of the Cost of Energy for the various configurations considered and for the current plant; the $\mathrm{COE}$ of configuration 6 is the lower $\left(\mathrm{COE}_{6}=0.133 € / \mathrm{kWh}\right)$, which corresponds to the maximum 
production of electricity. However, the Cost of Energy of configuration $4\left(\mathrm{COE}_{4}=0.135 € / \mathrm{kWh}\right)$ is very similar to the lowest one; considering the Net Present Cost (Fig.4(b)) and the Cost of Energy, configuration 4 is preferred over the configuration 6 . In Fig. 8 the $\mathrm{CO}_{2}$ emissions for the configurations, are shown; it is calculated as the sum of the part emitted by the internal combustion engine and the one related to the electricity absorbed by the main grid, through the emission factor of the Italian grid that is $523 \mathrm{~g} / \mathrm{kWh}$.

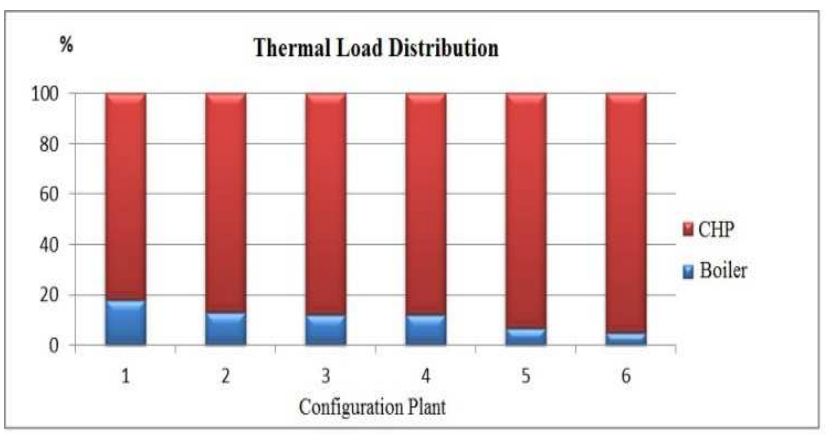

Fig -6: Thermal load distribution for the six configurations considered.

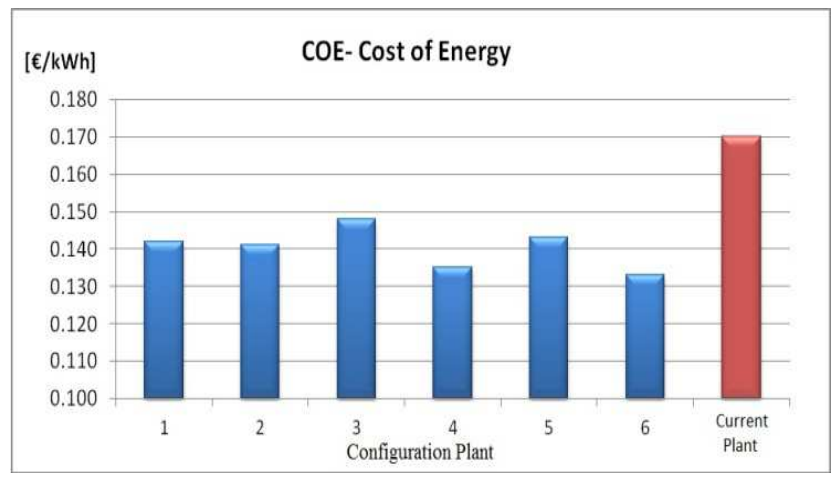

Fig-7: Cost of Energy for the six configuration considered and the current plant.

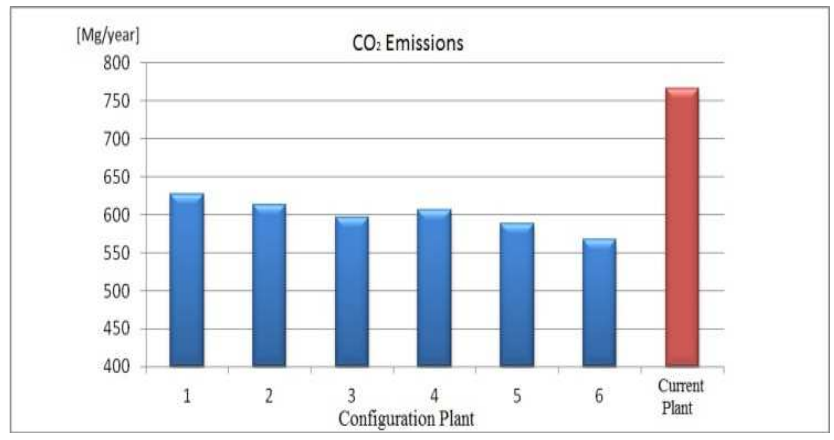

Fig -8: CO2 emissions for the six configurations considered and the current plant.
Therefore, configuration 4 represents a good compromise with a low COE, which is much lower than the one of the current plant $\left(\mathrm{COE}_{\mathrm{cp}}=0.170 € / \mathrm{kWh}\right)$; the limitation of the electrical absorption at $150 \mathrm{~kW}$ is a preferable solution for the CHP, which works for less hours per year, compared with configuration 6 , determining a decrease of costs of maintenance and natural gas consumption. The benefits of configuration 4 , compared to the current plant, are: an energy saving of $97500 € /$ year, a decrease of COE from $0.170 € / \mathrm{kWh}$ to $0.135 € / \mathrm{kWh}$ and a decrease of $\mathrm{CO}_{2}$ emissions of 139 $\mathrm{Mg} /$ year. The Primary Energy Saving (PES) index, expressed in Eq.1, for configuration 4 is $34.5 \%$, equivalent to 71.6 tep.

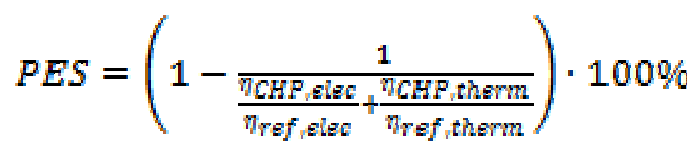

\section{MULTI-ENERGY SYSTEM WITH ELECTRIC STORAGE}

In the next few years, a quick and extensive diffusion of energy storage systems, is expected. Conventional power plants are forced to work with high variations, determining the instability of the main grid, because of the increase of energy production from renewable sources and to their nonprogrammability. The storage system represents a solution for this problem, by: limiting the effects of intermittency [10], separating the time energy production from renewable sources and its consumption and leveling the energy dispatched to the grid. Moreover, in countries where the difference of cost of energy is high, between the peak hours and the night hours, the possibility of making profits is realistic [11]. In this study, an evaluation of the effects produced by the adoption of three different energy storage system, has been performed. The systems considered are: the $\mathrm{Pb}-\mathrm{Ac}$ batteries [12], which represent a proven and reliable technology, even if they are characterized by a short life and a low efficiency; the Flywheels, which are kinetic energy storage systems characterized by a high efficiency and a high unit cost; the Micro-Caes (compressed air energy storage), characterized by low efficiency, an intermediate unit cost and long life [13]. In Fig. 9(a) are shown the characteristics of the three storage systems [14] and in Fig. 9(b) is shown the configuration plant with the Pb-Ac, Flywheels and Micro-Caes. For each technology of storage system, several sizes (electric capacities) have been considered: $25 \mathrm{kWh}, 50 \mathrm{kWh}, 100 \mathrm{kWh}$, $150 \mathrm{kWh}$ and $200 \mathrm{kWh}$, in order to evaluate their effects on the energetic and economic parameters and to optimize the system. In Fig.10 is shown the Cost of Energy (Fig.10(a)) and the Operating Cost (Fig.10(b)) of the multi-energy system, using different sizes of each storage system, compared with the values (continuous lines) without the energy storage. As it can be seen in Fig.10, the multi-energy system equipped with Micro-Caes or $\mathrm{Pb}-\mathrm{Ac}$ batteries, has a competitive Cost of 
Energy up to the size of $100 \mathrm{kWh}$, while the Flywheel system is disadvantaged by its high cost of investment.

(a)

\begin{tabular}{|c|c|c|c|}
\hline Electric Storage & Efficiency & $\begin{array}{c}\text { Life } \\
{[\text { year] }]}\end{array}$ & $\begin{array}{c}\text { Unit Cost } \\
{[\mathbf{E} / \mathbf{k W h}]}\end{array}$ \\
\hline $\mathrm{Pb}-\mathrm{Ac}$ & $75 \%$ & $5 \div 10$ & 200 \\
\hline Flywheel & $90 \%$ & $>20$ & 2000 \\
\hline Caes & $63 \%$ & $>20$ & 700 \\
\hline
\end{tabular}

(b)

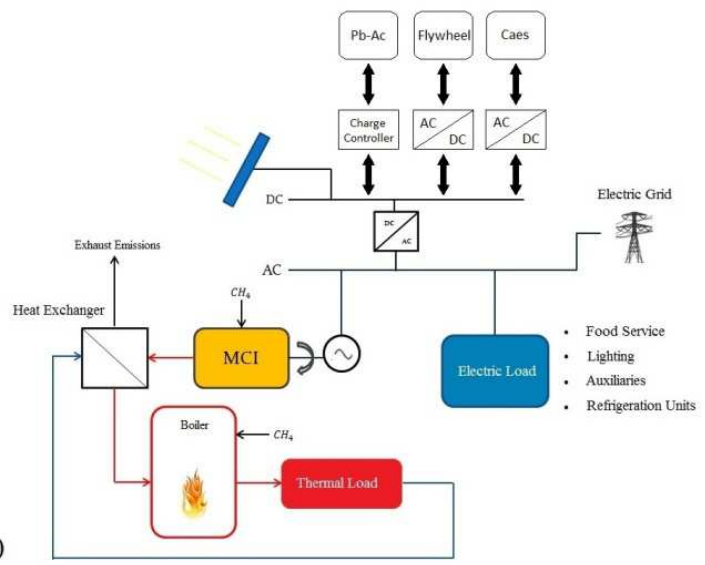

Fig -9: (a) Characteristics of the three storage systems considered; (b) Configuration plant of the multi-energy system with the three storage systems considered.

(a)
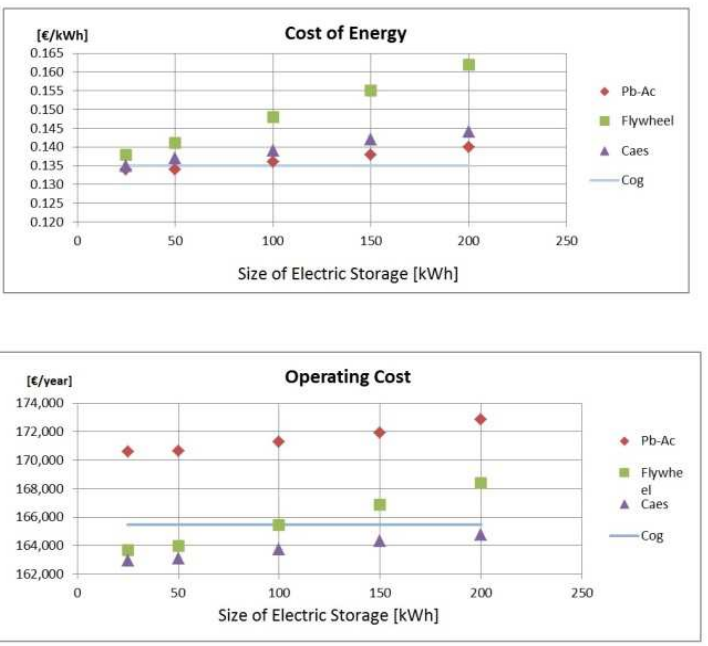

Fig -10: Cost of Energy (a) and Operating Cost (b) of the multi-energy system with different sizes of each storage systems, compared with the values (continuous lines) without storage system.
The annual operating costs for electricity and heat supply are lower for each size of Micro-Caes considered and for Flywheels, up to the size of $100 \mathrm{kWh}$. This trends are due to operation of the storage system: during the evening and the night it is charged, while it is discharged during the hours when the cost of electricity is high. In Fig. 11 are shown the daily charge/discharge trends of each storage system considered (size $50 \mathrm{kWh}$ ). As it can be noticed (Fig.12) the model prefers to discharge the storage system during the central hours of the day or when the photovoltaic production decreases, causing a time-shift of the peak of electric power requested from the grid (as shown in Fig.13). It produces benefits for the main grid, which is particularly congested during the central hours of the day, when industrial plants and most of the users are fully operative.
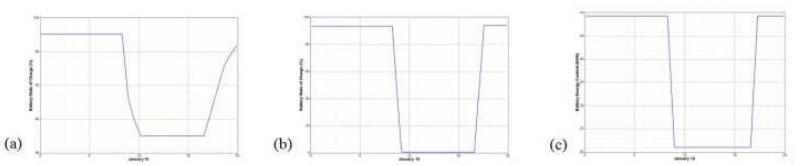

Fig -11: Daily charge/discharge trends (battery state of charge during a day) for the three storage systems, characterized by a size of $50 \mathrm{kWh}$ : (a) Pb-Ac batteries, (b) Flywheels, (c) MicroCaes.

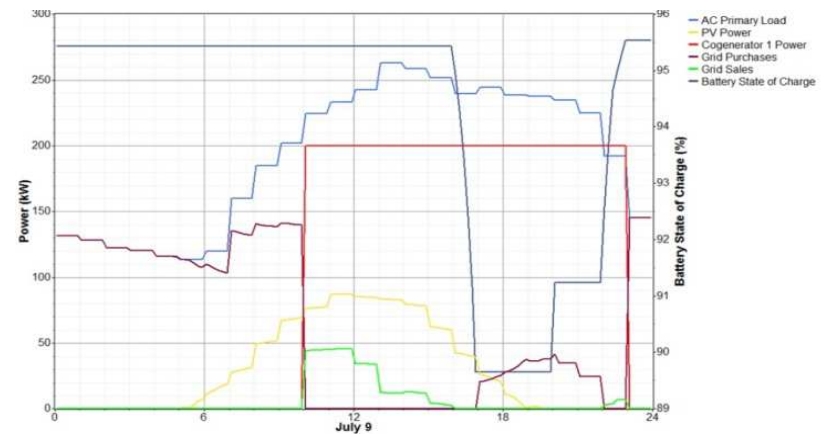

Fig -12: Operation time series for each component of the multi-energy system, equipped with a $\mathrm{Pb}-\mathrm{Ac}(50 \mathrm{kWh})$, during a summer day.

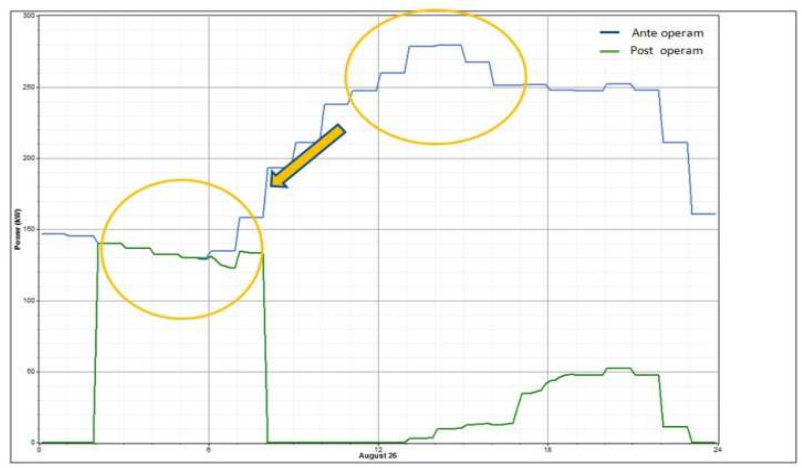




\section{CONCLUSIONS}

In order to face the increasing growth of energy consumption of the modern society and to reduce the emissions of greenhouse gases in compliance with international agreements, the problem of energy saving related to the responsible utilization of the energy sources is becoming important. The energy upgrading of the existing buildings can represent a valid contribution. In this study, a method for the energy upgrading has been proposed; an energy-intensive user, characterized by outdated plants, has been considered and an alternative solution has been evaluated. The results obtained are: an operating cost reduction of $97510 € /$ year; a cost of energy reduction (from $0.170 € / \mathrm{kWh}$ to $0.130 € / \mathrm{kWh}$ ); a reduction of $\mathrm{CO}_{2}$ emission of $139 \mathrm{Mg}$ /year. Furthermore, three different energy storage systems has been considered: $\mathrm{Pb}-\mathrm{Ac}$ batteries, Flywheels and Micro-Caes. The results show that storage systems and CHP are effective in co-operation, during the hours of peak load demand. The model proposed in this study is a flexible system and it has a positive impact on the main grid; moreover, the presence of storage systems produces an increase on the flexibility, through interactions with the components of the multi-energy system. A systematic application of this kind of systems can produce a significantly reduction of electricity absorbed from the main grid, producing in turn several benefits, such as a reduction of $\mathrm{CO}_{2}$ emissions and a time-shift of the peak of electric power requested from the grid, which produces a decongestion of the main grid in the central hours of the day.

\section{REFERENCES}

[1]. Directive 2009/28/EC of the European Parliament and of the Council of 23 April 2009 on the promotion of the use of energy from renewable sources and amending and subsequently repealing Directives 2001/77/EC and 2003/30/EC.

[2]. Directive 2004/8/EC of the European Parliament and of the Council of 11 February 2004 on the promotion of cogeneration based on a useful heat demand in the internal energy market.

[3]. Manwell J.F., Hybrid energy system, Encyclopedia of Energy Volume 3, 2004.

[4]. ASCOMAC COGENA: i vantaggi dei sistemi SDC/RIU/SEU abbinati a reti intelligenti http://www.casaeclima.com/index.php?option=com_content $\&$ view $=$ article $\& i d=16038$ :ascomac-cogena-i-vantaggi-deisistemi-sdcriuseu-abbinati-a-reti-intelligenti\&catid=1:latestnews \&Itemid $=50$.

[5]. A. Sharif, A. Almansoori, M. Fowler, A. Elkamel, K. Alrafea, Design of an energy hub based on natural gas and renewable energy sources. International Journal of Energy Research. 2013.

[6]. E. Fabrizio, M. Filippi, La valutazione del sistema multienergia a servizio dell'edificio: procedura di simulazione dinamica attraverso la metodologia dell'energy hub, $63^{\circ}$ Congress ATI, 2008.

[7]. M. Brenna, M.C. Falvo, F. Foiadelli, L. Martirano, F. Massaro, A. Vaccaro, Challenges in Energy system for the smart-cities of the future. 2nd IEEE ENERGYCON Conference \& Exhibition, 2012 / Future Energy Grids and Systems Symp.

[8]. www.trnsys.com

[9]. www.homerenergy.com

[10]. Lund H, Mathiesen BV, Energy System Analyses of $100 \%$ renewable energy system- The case of Denmark in year 2030 and 2050. Energy, May 2009.

[11]. Inage S-I. Prospect for a large scale energy storage in decarbonized power grids. International Energy Agency. 2009. [12]. F. Alessandrini, G. B. Appetecchi, M. Conte, Studio di fattibilità tecnica sull'applicabilità delle batterie al litio nelle reti elettriche - Stato dell'arte e limiti scientifici e tecnologici, Report, ENEA, 2010.

[13]. Wenyi, Yongping Yang, A novel hybrid-fuel Compressed Air Energy Storage System for China's Situation, ECOS, 2012.

[14]. Helder Lopes Ferreira, Raquel Garde, Gianluca Fulli, Characterization of electrical energy storage technologies, 2012.

\section{BIOGRAPHIES}

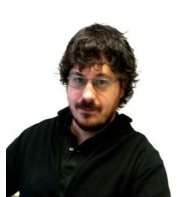

Simone Bottillo was born in Rome, Italy, on August 26, 1982. He received the bachelor's degree and the master's degree in Mechanical Engineering, from University of Rome "Roma Tre" (Italy) in 2007 and 2012, respectively. From January 2013 he is Temporary Research Associate November 2013 he is Ph.D. Student in Energy and Environment at DIAEE Department of University of Rome "La Sapienza". He is co-author of some scientific works about urban comfort and urban heat exchanges, published in international journals and conferences.

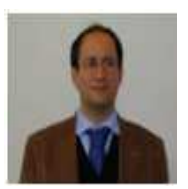

Luca Cedola, born in Rome Italy on 25/07/1969 received the M.S. degree in Mechanical Engineering, and the Ph.D. degree in Energy and Environmental Management Systems in 1996 and 1999, respectively. From 2000 Research Associate and from 2009 Assistant Professor at the Department of Mechanical and Aeronautical Engineering University of Rome "Sapienza" A significant part of the research activity has also been developed in the framework of private contracts signed from my department with public bodies and private companies in the R\&D field, industrial innovation and technology, with particular attention to SMEs, in the field of renewable energy. He is author or co-author of about 30 scientific works, published in prominent international journals and conferences on Energy and Environmental Management systems. 


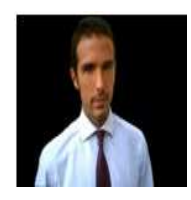

Roberto de Lieto Vollaro was born in Rome November 25, 1977, residing in Rome. Bachelor's Degree (five-year vo) in Mechanical Engineering at the University of Roma Tre on July 13, 2003. PhD in Industrial Engineering XIX cycle, at the University of Perugia and was awarded the title of Doctor of Philosophy in "Industrial Engineering" on 12 February 2007. Professor of Physics and Environmental Technical Physics since 2005 at the Faculty of Architecture Ludovico Quaroni's La Sapienza University for the Degree of Architecture EU Adjunct Professor since 2009 teaching in Acoustics and Lighting The day of December 16, 2011 becomes Research Professor "Confirmed" at the Department of Mechanical and Industrial Engineering at the University of Roma Tre. On 4 May 2012 he was elected with 287 votes as representative on the Board of Directors of the University of Roma Tre. On June 19, 2012 becomes Official Member of the Budget Committee and the Commission supplies, services and spaces of the University of Roma Tre.

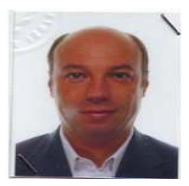

Andrea Vallati was born in Roma, Italy, on October 16, 1970. He received the M.S. degree in Mechanical Engineering, and the Ph.D. degree in Applied Physics, from University of Ancona (Italy) in 1997 and 2001, respectively. From 2006 he served as Assistant Professor at the Department of "Fisica Tecnica" of the same University. Since 2005 he is Professor of Energy and Applied Physics at the Faculty Engineering of "Sapienza" University of Rome. He is author or co-author of about 40 scientific works, published in prominent international journals and conferences on heat transfer, thermodynamics and acoustics. 